\title{
Computational Study of Viscous Flow in a Scramjet
}

\author{
Jeevan $\operatorname{Rao}^{\dot{A}^{*}}$, Bhargav $^{\dot{A}}$, Krupakar Pasala $^{\dot{A}}$ and Srinivasa $\operatorname{Rao}^{\dot{A}}$ \\ ${ }^{\dot{A}}$ Dept. of Aeronautical Engineering, Vardhaman College of Engineering, Hyderabad. \\ Accepted 10 January 2014, Available online 01 February 2014, Special Issue-2, (February 2014)
}

\begin{abstract}
The present work describes the study on complex internal viscous flow in a scramjet. The dissociation of air in complex scramjet model using two dimensional computational fluid dynamics and also at fuel-off conditions on combustion chamber is presented. The results of free-stream flow attio Mach 4 at different altitudes viz $25 \mathrm{~km}, 30 \mathrm{~km}$ and $35 \mathrm{~km}$ in the combustion chamber are compared. For computational aid Green Gauss cell based gradient option is used with steady time and absolute velocity formulation.
\end{abstract}

Keywords: Scramjet, Fuel-off, CFD etc

\section{Introduction}

Major Development has been made in hypersonic engine propulsion(HEP) devices. such as scramjet engines in recent years as the 21 st century unfolds a innovative engine technology is aiming to fly craft at high Mach speeds and seamlessly integrate air-to-space operations. The supersonic combustion ramjet and scramjet, uses no rotating parts, will power vehicles hundreds of miles in minutes and will make fast global travel and affordable access to space a reality. The first scramjet-powered aircraft flew on its individual. On the afternoon of March 27, an unpiloted Scramjet, a National Aeronautics and Space Administration (NASA) where the Scramjet(X43A) separated from the booster, and its scramjet engine fired for a planned 10-s test, achieving an unbelievable Mach 7, or 5,000 mph.

And many hydrogen and hydrocarbon-fueled engine programs have helped scramjet technology evolve to its current state, provided the foundation for the power plant used during the X-43A's recent flight. and generally the experimental setup is more to complex compared the computational simulation and analysis, and the CFD is an efficient, safe and coast effective tool to sustain ground testing and real tests for design modifications are important testing experimentally. this can also important to complex flow phenomena like flow separation, turbulence chemistry reactions...etc many CFD works have been conducted in the development methods of the scramjet technology which has highlighted the extreme difficulty associated with capturing even just the turbulent non-reacting flow in the combustor. Karl et al(2008)presented, a CFD study of the experimental tests carried out by Schramm et al(AIAA Paper 2008-2547) at HEG, DLR. In their computational simulations for a

*Corresponding author: Jeevan Rao

DOI: http://dx.doi.org/10.14741/ijcet/spl.2.2014.89 complete scramjet model with fuel-off conditions and fuelon conditions at Mach 7.4 using DLR-TAU code and RANS approach were presented which showed very good agreement between the wind tunnel test and CFD results. Rana et al(2009) also conducted a full flow field analysis of the scramjet geometry with the fuel-off condition at Mach7. 4 using High Resolution Method (HRM). Comparison with the CFD study of Karl et al(2008) and the experimental results of Schramm et al(AIAA Paper 2008-2547) have demonstrated that methodology provides good conformity with the experiments and excellent agreement with the CFD simulations at DLR using much less complex formulation but higher order methods. The U.S. Air Force and Pratt \& Whitney ground-tested the first un cooled hydrocarbon-fueled scramjet engine simulation at Mach 4.5-6.5 in 2001. This partnership also demonstrated in 2003 a scramjet made from nickel-based alloys and cooled by its JP7 jet fuel. The 2003 engine has the probable to power Advanced missiles, aircraft, and access-to-space Flights and Last year, the Defense Advanced Research Projects Agency, U.S. Navy, Boeing, Aero jet, and Johns Hopkins University also ground-tested a scramjet engine, which was constructed mainly from nickel alloys, powered by JP10 jet fuels, and planned exclusively for hypersonic missiles.

This paper aims to study the scramjet engine with fueloff conditions of free-stream flow at Mach 4 at different altitudes viz $25 \mathrm{~km}, 30 \mathrm{~km}$ and $35 \mathrm{~km}$ in the combustion chamber are compared by using numerical analysis of the computational setup.

\section{Literature Survey}

Professor Michael K. Smart, studied on challenges in the design of the inlet or entrance of these hypersonic airbreathing engines are scramjet and ramjet. Kyung Moo Kim et.al [vol 47,2004] worked on the subject of 
Numerical study on supersonic combustion with cavitybased fuel injection Specified wall angle of hollow space enhances then the combustion efficiency is improved results indicating, but total pressure loss increased. When the offset ratio of upper to downstream depth of the cavity increases, the combustion efficiency as well as the totalpressure loss decreases. Yuan shengxue [February 1999 ] worked on the subject of supersonic combustion. The deflagration calculations in supersonic flow shows that the entropy enhancement and the total pressure loss of the combustion products may decrease with the increase of combustion velocity are the results produced. The oblique explosion wave angle may not be controlled by the wedge angle under weak under driven solution circumstances and be determined only by combustion velocity. Gruenig and F. Mayinger worked on the topic of Supersonic combustion of kerosene/h2-mixtures in a model Scramjet combustor the temperature level is partly achieved by the oblique shock waves in the supersonic flow with increasing combustor area ratio. K. Kumaran and V. Babu [2009] worked on the topic of Investigation of the effect of chemistry models on the numerical predictions of the supersonic combustion of hydrogen the multi direction chemistry predicts higher and wider spread heat release than what is predicted by single step chemistry. T. Cain and C. Walton [RTO-TR-AVT-007-V2 ] worked on the topic of review of experiments on ignition and Flame holding in supersonic flow the low combustor entry temperature is desirable /essential due to intake and nozzle boundaries. Hydrogen and hydrocarbon the optimum temperature/pressures are in regions in which ignition delay is very sensitive to temperature, varying from $0.1 \mathrm{~ms}$ to $>10 \mathrm{~ms}$. At low Mach number and static temperatures but at these conditions combustion results in free subsonic regions with very high turbulence.

A. R. Srikrishnan and j. Kurian et.al. [vol 107,1996] worked on the topic of An Experimental Investigation of Thermal Mixing and Combustion in Supersonic Flows A petal nozzle can reached nearly uniform a specific temperature and momentum fields by using mixing duct are results produced. The petal nozzle also results in better combustion, when it is used to inject the rich mixture gases into a supersonic combustor. Temperature and pressure rises were measured and the supersonic combustion efficiency was found to be of the order of $60 \%$. The performance of a conventional conical nozzle was found to be much inferior to that of the petal nozzle under identical conditions.

M Deepu [vol.88,may 2007] worked on the topic of Recent Advances in Experimental and Computational Analysis of Scramjet Combustor Flow Fields the enhancement in jet to free stream momentum flux ratio will result in the increase of jet penetration to free stream for all kinds of jets. Injector orientation plays an major role in the strength of the bow shock wave, with the shocks formed by oblique injector being substantially weak compared to transverse injector. Arif Nur HAKIM, Shigeru ASO et.al. [vol.68 march 2008] worked in the name of Experimental Study on Effects of Shock Wave Impingement on Supersonic Combustion the shock wave impingement improves the combustion and shock induced divided region from resuls, which is experiential at stronger shock wave impingement, could worked as flame-holder.

The intent of the current research is to investigate the effect incident shock wave impingement upstream and downstream of the injector on the flow field, mixing and combustion of a hydrogen jet in evaluation with the case that no incident shock is present.

\subsection{Scramjet Inlets}

Hypersonic inlets used in scramjets classified into threedifferent categories, based on the type of compression that is utilized. These are (i) external compression, (ii) mixed compression and (iii) internal compression.

A schematic of an external compression inlet is shown in Fig. 1. Here, as the name suggests, all the compression is performed by flow turning in one direction by shock waves that are external to the engine. These inlet configurations have large cowl drag, as the flow entering the combustion chamber is at a large angle relative to the free stream flow, and external compression inlets are selfstarting and spill out flow when operated below the design Mach number (this is a desirable feature for inlets that must operate over a large Mach number range and high altitudes). A schematic of a mixed compression inlet is shown in Fig. 2. Here the compression is performed by shocks both external and internal to the engine, and the angle of the external cowl relative to the free stream velocity can be made very small to minimize external drag.

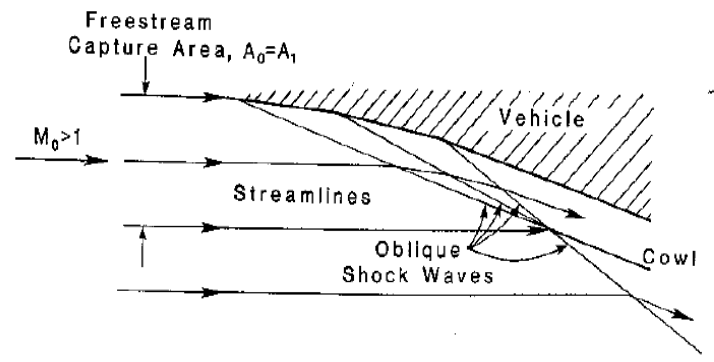

Fig. 1. External compression inlet (Heiser and Pratt)

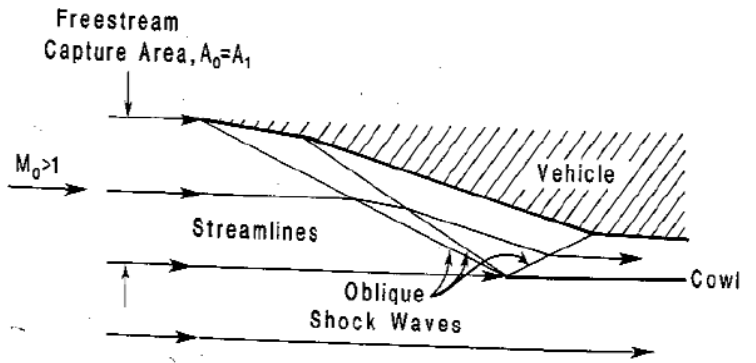

Fig. 2. Mixed external and internal compression inlet

These inlets are typically longer than external compression configurations, but also fall flow when operated below the design Mach number. Based on the amount of internal compression, however, mixed compression inlets may need variable geometry in order to start. A diagram of an internal compression inlet is shown in Fig. 3. Here all the compression is performed by the shock waves that are 
internal to the engine. This type of inlet can be less than a mixed compression of inlet, but it does not permit easy integration with a hypersonic space vehicle. It maintains full capture at Mach numbers lower than the design considerations, but its most significant control is that extensive variable geometry is always required for it to start.

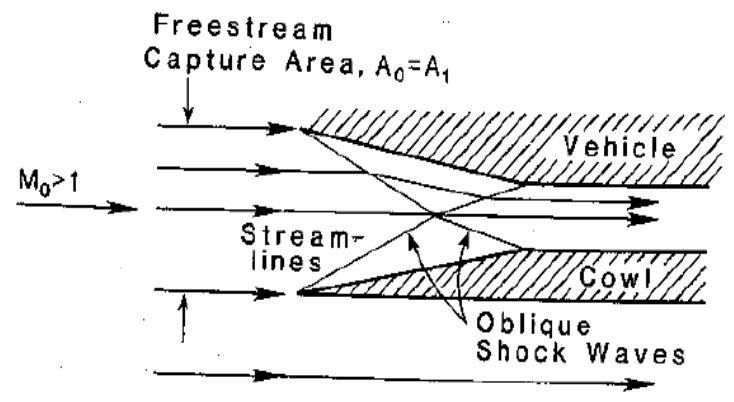

Fig. 3. Internal compression inlet

\section{Geometry and computational setup}

The schematic diagram of ramjet engine shows in fig. 4 . The scramjet engine is composed of three main parts; Inlet ramp, combustion chamber and exhaust nozzle. To be identified, there is a bleed-off section between the inlet ramp and combustion chamber. the major purpose of this section is to take the flow inside of the combustion chamber as smooth as possible by dropping of the boundary layer and the entropy layer as well as disgorging the shock formation by front edge area of the cowl.

The detail dimensions of scramjet are given in fig. 5 . The inlet ramp is 18 degrees. the half angle wedge with a width of $100 \mathrm{~mm}$ and the leading edge of the top wall of the cowl and the bottom wall of combustion chamber are beveled to be 18 degrees. and 16.5 degree., with bluntness diameters of $0.4 \mathrm{~mm}$ and $0.2 \mathrm{~mm}$, correspondingly.

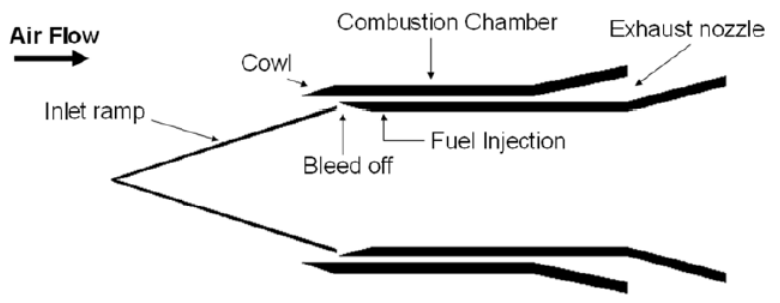

Fig.4 Schematic diagram of scramjet engine

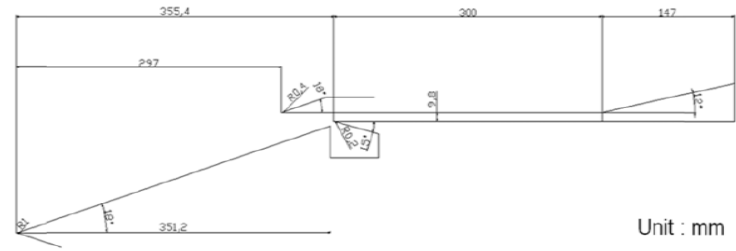

Fig .5 Detailed dimensions of scramjet engine.

The combustion chamber is $9.8 \mathrm{~mm}$ in height and $75 \mathrm{~mm}$ in width with overall length about $300 \mathrm{~mm}$. The dimensional details of scramjet engines can be found in references 1,3,7 and 12 . The blunt leading edge at the bottom wall of combustion chamber yields a bow shock and a train to reflected oblique shocks inside the combustion the combustion chamber which increase the chamber pressure in the directed path.

In ordr to reduce the complexcity of computatinal resources, Only was the half-engine and part nozzle model crossection model simulated. the full computational setup applied to scramjet simulations is shown in fig. 6 , along with corsponding boundary conditions. The domain is bounded between the free stream flow and the supersonic outlet.Coputational analysis is split into two sections; the first section deals with the $2 \mathrm{D}$ analysis of full domain with coarse structural grid and the second section deals with the 2D analysis of the simplified domain with fine structural grid,including only the combustion chamber and exhaugst nozzle sections, at fuel off-conditions.the purpose of the 2D full setup simulation extract the initial conditions for combustion chamber entrance in the simplifed setup simulation,o that the flow inside the combustion chamber is a rectungular section,this will help future CFD studies of the combustion system with very fine grids and fuel-on cases where the shock wave can play very vital role.

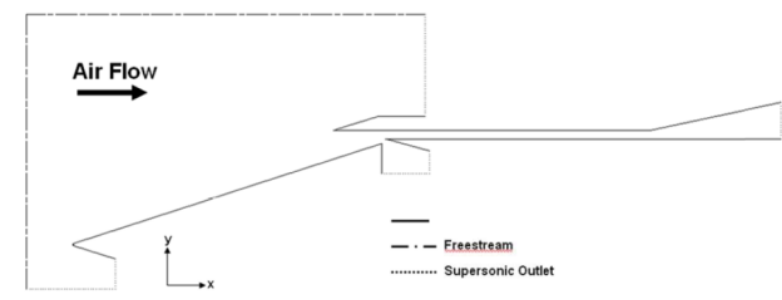

Fig. 6.computational setup and boundary conditions applied to scramjet engine.

\subsection{Placing the graphs}

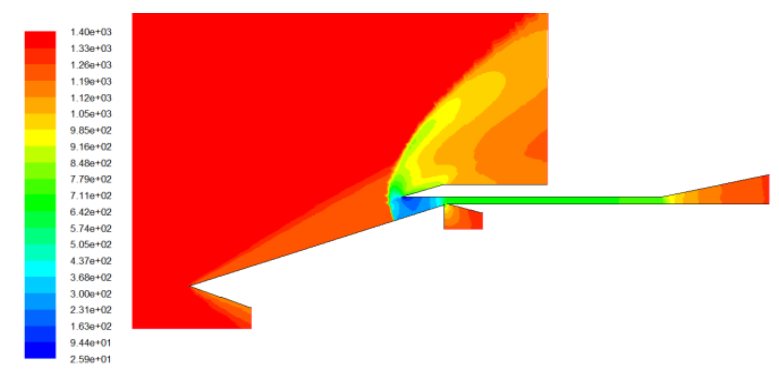

Contours of Velocity Magnitude (m/s) Oct 19, 2013
FLUENT 6.3 (2d, dp, pons)

(a)

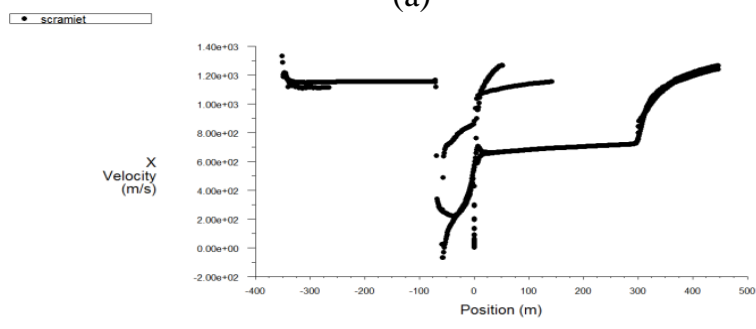

x veloctiy

(b)

Fig. 7 (a)Contours of the velocity magnitude of the flow field; (b)velocity variations with respective positions of flow field;

482 International Conference on Advances in Mechanical Sciences 2014 

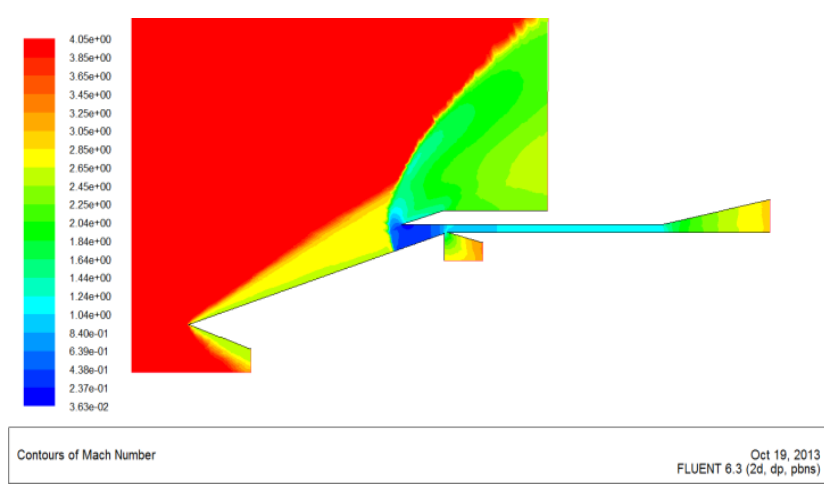

(a)

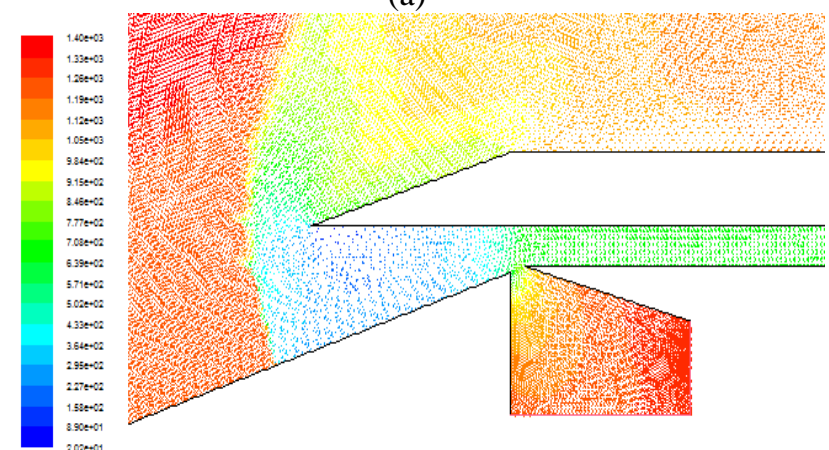

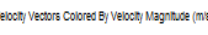

(b)

Fig. 8 (a)Contours of mach number of the flow field; (b)A view of the velocity vectors colored by velocity magnitude.

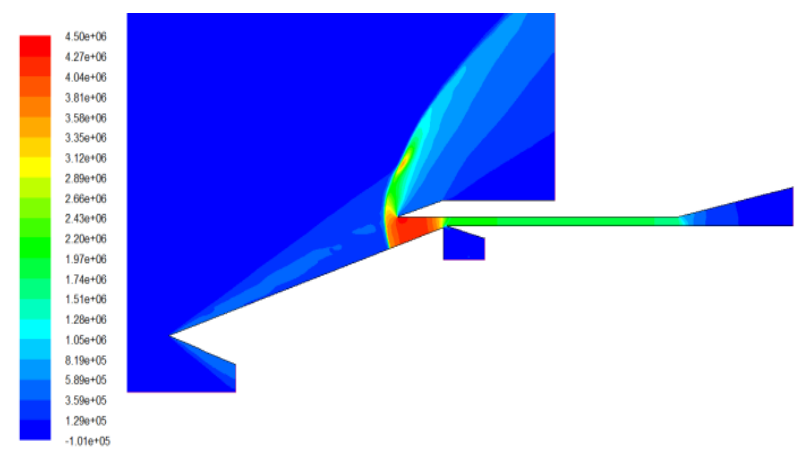

Contours of Static Pressure (pascal) Oct 19, 2013
FLUENT 6.3 (2d, dp. pbns)

(a)
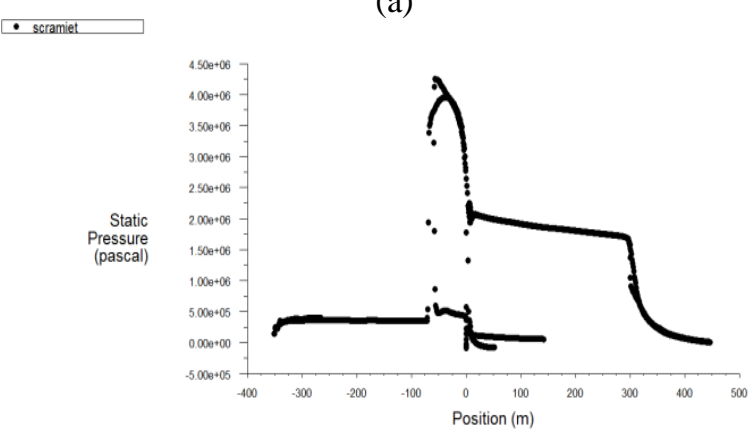

Static Pressure Oct 19, 2013
FLUENT 6.3 (2d, dp, pons)

(b)

Fig. 9 (a)Shows the contours of static pressure and shock formation;(b)It indicates the static pressure variation with respective position.

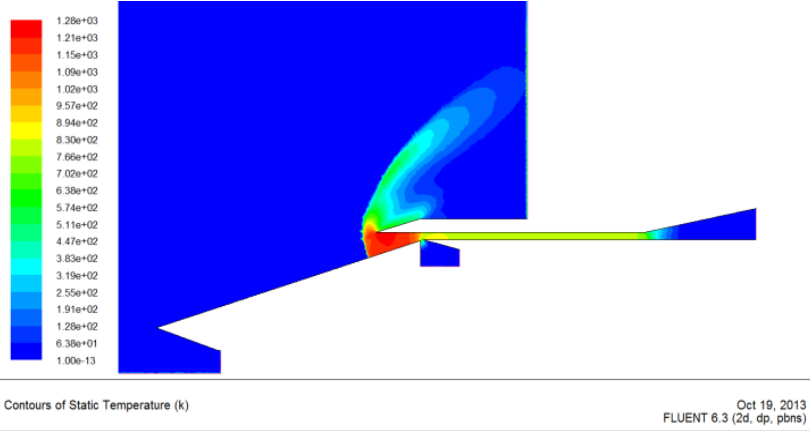

(a)

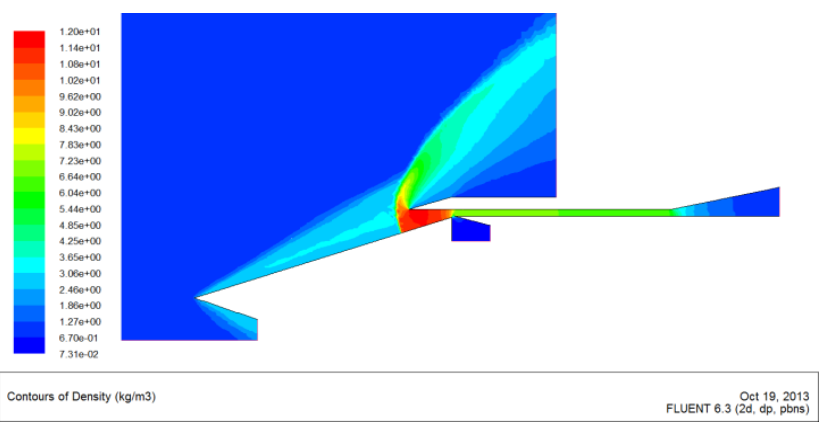

(b)

Fig. 10 (a)shows the static temperature of scramjet model; (b)it indicates the density and shock formation.

\section{1(a)Results and discussions}

Figure 7(a) shows the velocity contours patterns around Scramjet engine at the fuel-off condition. A strong shock wave generated at the scramjet engine inlet ramp is clearly observed. With the angle of attack of $3.02 \mathrm{deg}$., the coming flow has a small descending velocity section. Not total the coming flow is captured. Components of inlet incoming air flow over the cowl and components spill out to the bleed-off section. Figure 8(a) Indicate the Mach number contour of the complete flow field and Fig. 8(b) demonstrates a clear view of the Mach number isolines around the bleed-off area of scramjet section. As observe, after the bow shock produced by the cowl, the Mach number of the flow is about 4 . The flow then enters the rectangular combustion chamber at Mach number 3.1 with uniform flow conditions..Figure 9(a) Shows a close up view of the flow and streamline patterns around the bleedoff area of the scramjet engine. The bow shock waves from the leading edges of the cowl and the scramjet model combustion chamber bottom wall and the Prandtl-Meyer extension fan generated at the rear edge of the inlet ramp are clearly depicted. A complex interaction between these two shock waves and an expansion fan results in a complex flow and turns parts of the flow into the bleed-off section. This complex contact flow is very sharply spilled out of the system at this section and makes the flow inside the combustion chamber as flat as possible and free of discontinuities. On the other hand, as observe a shock wave generated from the bottom wall of the combustion chamber still goes into the combustion chamber and therefore yields a system of shock waves reflected along the length of the combustion chamber. Fig 9(b)The static pressure is varying with respective position in $\mathrm{x}$-direction 
flow pressure rises up to 4 pa and linearly fall down to 2 pa and after that up to some constant conditions reflected along the length of the combustion chamber. Fig.10(a) The diagram shows the static temperature at the cowl section and the entrance of bleed-off section is high. and Fig(b) shows the contours of density at inlet ramp to cowl section.

\subsection{Free stream conditions}

The free stream conditions are given by Karl et $a l^{4}$ adopted in present study for the full computational simulation and are listed in Table1. The flow is coming from left of the section to right. The free velocity is about mach number 4 which can divided in to $\mathrm{x}$ and $\mathrm{y}$ parts according to the angle of attack of $3.02 \mathrm{deg}$. The major components of the flow are $\mathrm{N}_{2}, \mathrm{O}_{2}, \mathrm{O}, \mathrm{N}$ and $\mathrm{NO}$ Experimental procedure parameters Free stream conditions of $2 \mathrm{D}$ intake $^{4}$

\subsection{Placing the tables}

\begin{tabular}{|l|l|l|}
\hline Property & Value & Units \\
\hline Velocity(x-dir) & 1180 & $\mathrm{~m} / \mathrm{s}$ \\
\hline Velocity(y-dir) & 0 & $\mathrm{~m} / \mathrm{s}$ \\
\hline Mach number & 4 & \\
\hline Pressure & $4.05 \mathrm{e}+03$ & $\mathrm{~atm}$ \\
\hline Temperature & $1.28 \mathrm{e}+06$ & $\mathrm{~K}$ \\
\hline $\mathrm{N}_{2}$ mass fraction & 0.74818 & \\
\hline $\mathrm{O}_{2}$ mass fraction & 0.21505 & \\
\hline $\mathrm{O}$ mass fraction & 0.00012 & \\
\hline NO mass fraction & 0.02302 & \\
\hline N mass fraction & 0.0 & \\
\hline
\end{tabular}

\section{Conclusions}

1.The complex internal viscous flow in the scramjet engine model was validated in this paper. Only fuel-off conditions at free stream flow of mach number 4 and different altitudes of $25 \mathrm{~km}, 30 \mathrm{~km}$ and $35 \mathrm{~km}$ conditions was simulated.

2.Total flow field analysis of the scramjet engine model geometry has been presented on a coarse grid.

3.The simulated computational structure, streamline pattern and mach number isolines are in good arrangement with those presented in the numerical simulations of (Rana et al 2009).

4.The computational domain simulation was used to take out the initial conditions for the combustion chamber inlet in the simplified computational domain simulation in order to have fine and sufficient grid to resolve the shock discontinuities, variations and viscous interactions.

5.The present simulated flow properties inside the combustion chamber will used in fuel-off conditions with combustion.

\section{References}

Chih-Yung Wen1,(1961), Numerical Simulation of Complex Internal Viscous Flow in the HyShot-II Scramjet Model, BCRIAJ,19,609-621.

Schramm, J. M., Karl, S., Hannemann, K., Mack, A. and Steelant, J., Ground Testing of the HyShot II Scramjet Configuration in HEG, AIAA Paper 2008-2547.

Jeung, I. and Choi, J., Numerical Simulation of Supersonic Combustion for Hypersonic Propulsion, 5th Asia-Pacific Conference on Combustion, Australia, 2005.

Karl, S., Hannemann, K., Mack, A. and Steelant, J., CFD Analysis of the HyShot II Scramjet Experiments in the HEG Shock Tunnel, AIAA Paper 2008-2548.

Kindler, M., Lempke, M., Blacha, T., Gerlinger, P. and Aigner, M., Numerical Investigation of the HyShot Supersonic

Combustion Configuration, AIAA Paper 2008-5167.

Hannemann, K. and Gardner A.D., Evaluation of Full-Engine Scramjet Technology, Report Number: DLR-IB 224-2004 A11, 2004.

Mack, A., Steelant, J., Schramm, J.M., and Hannemann. K., Sensitivity Analysis for the Hyshot Generic Supersonic Combustion Con_guration using CFD, ISABE-2007-1310, 2007

Rana, Z. A., Thornbery, B. J. R. and Drikakis, D., Simulations of the HyShot-II (Scramjet) Model Using High-Resolution Methods, AIAA Paper 2009-4844.

Shang, H.M., Chen, Y.S., Liaw, P., Shih, M.S. and Wang, T.S., Numerical Modeling of Spray Combustion with an Unstructured Grid Method, AIAA Paper 95-2781.

Professor Michael K. Smart,Chair of hypesonic Propulsion, Centre for Hypersonics, The University of Queensland Scramjet inlets.

Kyung Moo Kim 1, Seung Wook Baek and Cho Young Han, Numerical study on supersonic combustion with cavity-based fuel injection, International Journal of Heat and Mass Transfer, vol 47, 2004, pp.271-286.

Yuan Shengxue, supersonic combustion, vol. 42, no. 2, science in china (Series A), February 1999 ,

Gruenig and f. Mayinger, supersonic combustion of kerosene/h2mixtures in a model scramjet combustor, institute for thermodynamics, technical university Munich, and d-85747.

K. Kumaran and V. Babu, Investigation of the effect of chemistry models on the numerical predictions of the supersonic combustion of hydrogen, Combustion and Flame, vol 156, 2009, pp.826-841.

T. Cain and C. Walton review of experiments on ignition and flame holding in supersonic flow Published by the America Institute of Aeronautics and Astronautics, RTO-TR-AVT-007V2.

R. Srikrishnan, j. Kurian and v. Sriramulu an experimental investigation of thermal mixing and combustion in supersonic flows, combustion and flame, vol 107, 1996, pp.464-474.

J.D.Anderson Jr. Hypersonic and High Temperature Gas Dynamics AIAA Education

M Deepu Recent Advances in Experimental and Numerical Analysis of Scramjet Combustor Flow Fields, Vol. 88, May 2007.

Arif Nur HAKIM, Shigeru ASO and Yasuhiro TANI Experimental Study on Effects of Shock Wave Impingement on Supersonic Combustion Memoirs of the Faculty of Engineering, Kyushu University, Vol.68, No.1, March 2008 